\title{
In-vitro Assessment of Biological Properties of Lipids Isolated from Gonads of Stomopneustes variolaris ${ }^{\dagger}$
}

\author{
Karthih M.G. ${ }^{1}$, Gobalakrishnan M. ${ }^{1}$, Aranganathan L. ${ }^{1}$, Radhika Rajasree S.R. ${ }^{2, *}$ \\ 1 Centre for Ocean Research (DST-FIST Sponsored Centre), (MoES-ESTC Marine Biotechnological Studies), Sathyabama \\ Institute of Science and Technology, Jeppiaar Nagar, Rajiv Gandhi Road, Chennai -600119 \\ 2 Department of Fish Processing Technology, Kerala University of Fisheries and Ocean Studies (KUFOS), Panangad, \\ Cochin, Kerala - 682506 \\ * Correspondence: radhiin@gmail.com; \\ $\dagger$ Presented at International e-Conference on Bioengineering for Health and Environment (ICBHE 2020)
}

Received: 5.07.2020; Revised: 10.07.2020; Accepted: 12.07.2020; Published: 15.07.2020

\begin{abstract}
Lipid fractions of gonads present in sea urchins serves as a source of bioactive agents with potent pharmaceutical properties. The present study reports the in-vitro biological effects of lipids isolated from gonads of sea urchin: Stomopneustes variolaris collected from the East coast of India. The extracted lipids were characterized by spectroscopic techniques such as GCMS and FTIR and tested for in-vitro biological effects. GCMS analysis of the lipid extract detected high levels of hexa triacontane $(17.023 \%)$, tetratetracontane $(15.913 \%)$, and octacosane $(15.628 \%)$ and low concentrations of oleic acid (2.206\%) and sulfurous acid, pentadecy 2-propyl ester (1.744\%). FTIR analysis identified rich composition of functional groups present in the lipids such as $3418.93 \mathrm{~cm}^{-1}$ (hydroxyl), $2921.08 \mathrm{~cm}^{-}$ ${ }^{1}$ and $2854.81 \mathrm{~cm}^{-1}$ (alkane), $2660.69 \mathrm{~cm}^{-1}$ (carboxylic acid), $1596.11 \mathrm{~cm}^{-1}$ (amine), $1291.76 \mathrm{~cm}^{-1}$ (aromatic amine). The lipid fraction evaluated by agar diffusion assay measured in terms of zone of inhibition showed bactericidal effects against gram-positive bacteria: Streptococcus aureus $(30 \mathrm{~mm})$; Pseudomonas aeruginosa $(28.5 \mathrm{~mm})$ and gram-negative bacteria: Escherichia coli $(29.5 \mathrm{~mm})$; Klebsiella pneumonia $(27.5 \mathrm{~mm})$ and Vibrio cholera $(28 \mathrm{~mm})$ respectively. The lipid fraction also showed an effective anti-fungal effect against C.albicans $(25 \mathrm{~mm})$. Further, the lipid fractions showed good radical scavenging effect against total phenolic, flavonoid content (15.12 mg GAE/g and 32.72 $\mathrm{mg} \mathrm{QE} / \mathrm{g}$ ), and hydrogen peroxide radicals $\left(\mathrm{IC}_{50^{-}} 48.28 \mathrm{mg} / \mathrm{ml}\right)$ confirming its anti-oxidant potential. Based on the observed results, it was identified that the lipid fraction of gonads of Stomopneustes variolaris demonstrated various biological effects such as bactericidal, anti-fungal and radical scavenging activities which could have a great scope in the formulation of biopharmaceutical agents.
\end{abstract}

Keywords: Stomopneustes variolaris; Gonads; lipid fractions; FTIR; anti-bacterial.

(C) 2020 by the authors. This article is an open-access article distributed under the terms and conditions of the Creative Commons Attribution (CC BY) license (https://creativecommons.org/licenses/by/4.0/).

\section{Funding}

This research received no external funding.

\section{Acknowledgments}

This research has no acknowledgment.

\section{Conflicts of Interest}

The authors declare no conflict of interest.

https://conferenceproceedings.international 